\title{
Early sympathetic islet neuropathy in autoimmune diabetes: lessons learned and opportunities for investigation
}

\author{
Thomas O. Mundinger ${ }^{1,2}$ - Gerald J. Taborsky $\mathrm{Jr}^{1,2}$
}

Received: 29 December 2015 / Accepted: 23 May 2016 / Published online: 24 June 2016

(C) Springer-Verlag Berlin Heidelberg 2016

\begin{abstract}
This review outlines the current state of knowledge regarding a unique neural defect of the pancreatic islet in autoimmune diabetes, one that we have termed early sympathetic islet neuropathy (eSIN). We begin with the findings that a majority of islet sympathetic nerves are lost near the onset of type 1 , but not type 2 , diabetes and that this nerve loss is restricted to the islet. We discuss later work demonstrating that while the loss of islet sympathetic nerves and the loss of islet beta cells in type 1 diabetes both require infiltration of the islet by lymphocytes, their respective mechanisms of tissue destruction differ. Uniquely, eSIN requires the activation of a specific neurotrophin receptor and we propose two possible pathways for activation of this receptor during the immune attack on the islet. We also outline what is known about the functional consequences of eSIN, focusing on impairment of sympathetically mediated glucagon secretion and its application to the clinical problem of insulin-induced hypoglycaemia. Finally, we offer our view on the important remaining questions regarding this unique neural defect.
\end{abstract}

Keywords Autoimmunity · Diabetes $\cdot$ Glucagon $\cdot$ Human · Insulin-induced hypoglycaemia $\cdot$ Islet $\cdot$ Neuropathy Neurotrophins $\cdot$ Review $\cdot$ Rodent $\cdot$ Sympathetic nerves

Thomas O. Mundinger mundin@u.washington.edu

1 Division of Metabolism, Endocrinology and Nutrition, Department of Medicine, University of Washington, Seattle, WA 98105, USA

2 Veterans Affairs Puget Sound Health Care System, 1660 S. Columbian Way, Seattle, WA 98108, USA

$\begin{array}{ll}\text { Abbreviations } \\ \text { ALX } & \text { Alloxan } \\ \text { BB } & \text { Biobreeder } \\ \text { BDNF } & \text { Brain-derived neurotrophic factor } \\ \text { DAN } & \text { Diabetic autonomic neuropathy } \\ \text { eSIN } & \text { Early sympathetic islet neuropathy } \\ \text { IIH } & \text { Insulin-induced hypoglycaemia } \\ \text { LCMV } & \text { Lymphocytic choriomeningitis virus } \\ \text { NGF } & \text { Nerve growth factor } \\ \text { p75 } & \text { p7R } \\ \text { RIP-GP } & \text { Rat insulin promoter-glycoprotein } \\ \text { ROS } & \text { Reactive oxygen species } \\ \text { SSN } & \text { Somatosensory neuropathy } \\ \text { STZ } & \text { Streptozotocin }\end{array}$

\section{Introduction}

In 1921, before the discovery of the glucose-lowering agent, insulin, the prospects for individuals with type 1 diabetes were grim: morbidity and early mortality were both very high [1]. Insulin provided a life-saving treatment for this disease [1]. However, while early experience with this new treatment revealed that insulin injection reversed diabetic hyperglycaemia, it also occasionally caused hypoglycaemia, which in severe cases resulted in convulsions, coma or death. The discovery of a glucose-raising agent in pancreatic extracts [2], subsequently named glucagon, provided a potential treatment for this hypoglycaemia. It was later found that pharmacology mimicked physiology: in non-diabetic individuals insulin-induced hypoglycaemia (IIH) stimulated a marked increase in endogenous glucagon secretion [3], which in turn limited the severity of the hypoglycaemia and contributed to restoration of euglycaemia $[4,5]$. Unfortunately, the ability of individuals with type 1 diabetes to recover from hypoglycaemia after 
insulin injection is limited by a major impairment in their glucagon response to IIH [6], one that is present in the first year after diabetes onset [7]. This impaired glucagon response increases the risk of severe and prolonged hypoglycaemia, which is not only dangerous but also aversive [8]. To avoid possible hypoglycaemia, patients sometimes reduce their insulin dose or increase their carbohydrate intake, which decreases their compliance with intensive therapeutic regimes $[9,10]$. Such non-compliance may accelerate both the onset and the progression of the long-term complications of this disease [11-14].

In non-diabetic animals and humans, both branches of the autonomic nervous system and the adrenal medulla are activated by hypoglycaemia [15]. Because each of these can stimulate glucagon secretion [15], their combined activation makes a major contribution to the glucagon response to $\mathrm{IIH}$ [16]. Therefore, an autonomic defect is a strong candidate for being a contributor to the impaired glucagon response to $\mathrm{IIH}$ seen in patients with type 1 diabetes [6,7]. However, early in type 1 diabetes the responses of two of these inputs to the islet, namely parasympathetic neural activation [17] and adrenal medullary adrenaline (epinephrine) secretion [18], appear normal. Thus, if an autonomic defect in type 1 diabetes impairs the glucagon response to IIH, this defect is likely to occur in the third autonomic input to the islet, the sympathetic nerves. Therefore we looked for, and found, a major defect in the sympathetic innervation of the islet in autoimmune diabetes, one that we have termed early sympathetic islet neuropathy (eSIN).

\section{Characteristics of nerve loss}

\section{Marked loss of islet sympathetic nerves: identification and quantification}

A marked loss of islet sympathetic nerves is seen in all four animal models of immune-mediated diabetes that have been examined (see Table 1). The two models of spontaneous autoimmune diabetes, the biobreeder (BB) rat [19] and the NOD mouse [20], are characterised by a $70-90 \%$ loss of their islet sympathetic nerves. Similar results are observed in the rat insulin promoter-glycoprotein (RIP-GP) transgenic mouse in which immune-mediated diabetes can be induced by two different methods. The traditional method involves the injection of lymphocytic choriomeningitis virus (LCMV), which elicits an immune response that targets not only the viral envelope that naturally contains viral glycoprotein but also the islet beta cells that transgenically express viral glycoprotein. Immune attack on the latter leads to rapid beta cell destruction and subsequent diabetes. A more recently developed non-viral method of diabetes induction involves the administration of multiple, sequential, pharmacological agents which induce in the RIP-GP mouse immunological responses similar to those seen during the viral attack [21]. The loss of islet sympathetic nerves is approximately $80 \%$ using the viral method [22] and $60 \%$ using the non-viral method (Fig. 1). Importantly, the translational value of all four animal models has recently been established by the finding of an $80-90 \%$ loss of islet sympathetic nerves in humans with type 1 diabetes [23].

Islet sympathetic nerves have been specifically identified by immunohistochemistry using different antibodies in different species. For example, in the rat, an antibody against the vesicular monoamine transporter 2 was used [19] to target the membrane of small noradrenergic secretory vesicles [24]. In the mouse, a neurally specific antibody against neuropeptide tyrosine was employed [25] to target this peptidergic neurotransmitter located in large non-adrenergic secretory vesicles of sympathetic nerves [26]. In humans [23], an antibody against tyrosine hydroxylase was used to target this enzyme in the cytoplasm throughout the sympathetic neuron. The sympathetic marker used was selected for each species to minimise nonneural staining, which could obscure the fine nerve fibres and varicosities in the islet and thereby lead to underestimation of nerve area and nerve loss. For example, while vesicular monoamine transporter 2 is neurally specific in rat islets, it is expressed in beta cells of primates, including humans [27]. Similarly, some neuropeptide tyrosine antibodies also bind
Table 1 The phenotypic characteristics, mechanistic requirements and functional consequences of eSIN

\begin{tabular}{|c|c|c|c|c|c|c|c|}
\hline \multirow{2}{*}{$\begin{array}{l}\text { Model of autoimmune } \\
\text { diabetes }\end{array}$} & \multicolumn{4}{|c|}{ Phenotype } & \multicolumn{2}{|l|}{ Mechanism } & \multirow{2}{*}{$\begin{array}{l}\text { Dysfunction } \\
\text { Glucagon }^{\text {secretion }}{ }^{\mathrm{a}}\end{array}$} \\
\hline & Early & Sustained & Marked & $\begin{array}{l}\text { Islet } \\
\text { only }\end{array}$ & Infiltration & $\mathrm{p} 75^{\mathrm{NTR}}$ & \\
\hline $\mathrm{BB}$ rat & $\mathrm{D}$ & $\mathrm{D}$ & $\mathrm{D}$ & $\mathrm{D}$ & NT & NT & $\mathrm{D}$ \\
\hline NOD mouse & $\mathrm{D}$ & $\mathrm{D}$ & $\mathrm{D}$ & $\mathrm{D}$ & $\mathrm{D}$ & NT & $\mathrm{D}$ \\
\hline RIP-GP mouse & $\mathrm{D}^{2}$ & $\mathrm{D}^{1}$ & $\mathrm{D}^{2}$ & $\mathrm{D}^{2}$ & $\mathrm{D}^{1}$ & $\mathrm{D}^{1}$ & $\mathrm{D}^{1}$ \\
\hline Human type 1 & $\mathrm{D}$ & $\mathrm{D}$ & $\mathrm{D}$ & $\mathrm{D}$ & NT & NT & NT \\
\hline
\end{tabular}

${ }^{a}$ Impairment of sympathetically mediated glucagon secretion

$\mathrm{D}$, demonstrated; NT, not tested; $\mathrm{D}^{2}$, demonstrated in both viral and non-viral models; $\mathrm{D}^{1}$ demonstrated in the viral model yet not tested in the non-viral model 


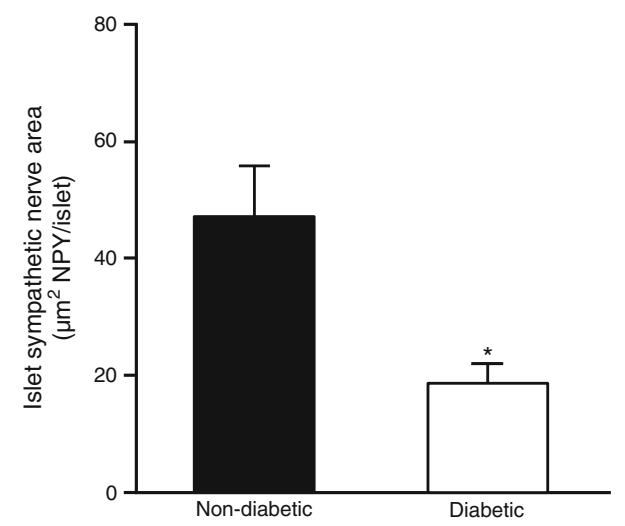

Fig. 1 Pharmacological (without virus) stimulation of an immune attack on the islet in RIP-GP mice leads to a marked loss of islet sympathetic nerves soon after diabetes onset. NPY, Neuropeptide tyrosine. ${ }^{*} p<0.05$ compared with non-diabetic control

peptide tyrosine tyrosine, which is found in alpha, beta, delta and $\mathrm{F}$ cells of mouse islets [28]. The finding that islet nerve areas, detected by three different antibodies and directed to three different sympathetic compartments, all decreased by a similar degree in animal models and humans with type 1 diabetes suggests that a marked loss of islet sympathetic nerves is a fundamental characteristic of autoimmune diabetes.

Just as antibody selection is important for specifically identifying islet sympathetic nerves, the method chosen for quantifying islet sympathetic nerves is important for accurately determining the magnitude of islet nerve loss in autoimmune diabetes. Experimental experience led us to quantify islet sympathetic nerves as 'nerve area per islet' rather than 'nerve density' (nerve area/islet area) because in some cases islet area can decrease secondary to beta cell loss without a change in the sympathetic innervation of the islet. In such situations, quantifying islet sympathetic nerve density would lead to the incorrect conclusion that the sympathetic innervation of the islet had actually increased. In contrast, quantifying islet sympathetic nerves by nerve area per islet would lead to the correct conclusion that the sympathetic innervation of the islet had not changed.

The best example of this phenomenon comes from experiments using beta cell toxins, either alloxan (ALX) or streptozotocin (STZ), which destroy beta cells by a mechanism that does not involve lymphocytic infiltration and therefore does not result in the loss of islet sympathetic nerves [19, 20]. High doses of either toxin produce a marked $(75 \%)$ and rapid ( $<1$ week) decrease in islet area [19, 20]. If nerve density had been used to quantify islet sympathetic nerves one would have concluded that the sympathetic innervation of the islet had increased threefold. This conclusion would be suspect because, although unmyelinated sympathetic nerves can sprout, arborise and grow, this process takes months, not days [29]. Alternatively, if one used nerve area per islet to quantify islet sympathetic nerves, one would conclude that the sympathetic innervation of the islet was unchanged $[19,20]$.
To test which of these two methods gave the best functional estimate of the sympathetic innervation of the islet, we activated the postganglionic nerves innervating the islet in both STZ-diabetic rats [30] and ALX-diabetic mice [20] and measured the resultant glucagon response. We found that the glucagon response was unchanged, not tripled, when compared with that of non-diabetic controls. We concluded that when autoimmune diabetes results in a decrease in islet area, the sympathetic innervation of the islet is best quantified as nerve area per islet to avoid underestimating the degree of islet sympathetic nerve loss.

\section{Islet selectivity of nerve loss}

If the loss of sympathetic nerves in autoimmune diabetes is due to a tissue-specific immune attack, it should occur only in the pancreatic islets and not in the surrounding exocrine pancreas. Indeed, there is no loss of exocrine sympathetic nerves in diabetic BB rats [19], diabetic NOD mice [20] or humans with type 1 diabetes [23], all of whom display a marked loss of their islet sympathetic nerves. Thus, islet-selective nerve loss is a defining characteristic of eSIN in autoimmune diabetes.

Given the presence of intact sympathetic axons in the adjacent exocrine pancreas, one might expect rapid reinnervation of the islets. For example, one of the major barriers preventing regrowth of nerves into denervated tissue, especially in humans, is the long distances involved [31]. However, the intact axons in the exocrine tissue surrounding the islet, which are the parent axons of islet nerves, have a remarkably short distance to grow in order to reinnervate the islet. Furthermore, these fine axons in the exocrine pancreas are unmyelinated, a requirement for nerve regrowth [31]. Finally, islets transplanted into non-diabetic animals are eventually reinnervated [29]. However, in human type 1 diabetes there is no significant reinnervation of the islet, even decades after the initial destruction of islet sympathetic nerves [23], a finding confirmed over months in the BB diabetic rat [19]. Apparently, some factor of the diabetic milieu inhibits the regrowth of islet sympathetic nerves, despite the short reinnervation distance. Diabetes is known to retard the regrowth of other nerves after crush injury or axotomy, as reviewed by Kennedy and Zochodne [32]. Several potential mechanisms have been proposed to mediate this effect [33-42]. An alternative hypothesis, specific to the islet, is that a loss of islet nerve growth factor (NGF) inhibits islet reinnervation. Three findings support this hypothesis. First, NGF is a potent growth factor for islet sympathetic nerves [43]. Second, NGF is produced by the islet beta cells $[44,45]$, which are destroyed in type 1 diabetes. Third, beta cells transplanted into nondiabetic animals are preferentially reinnervated compared with non-beta cells [46]. Thus, loss of beta cell-derived NGF may account for the failure of diabetic islets to reinnervate, 
thereby explaining the permanence of eSIN in autoimmune diabetes [19, 23].

\section{Autoimmune requirement for nerve loss}

While a role for the immune system in mediating the loss of sympathetic nerves was first suggested by this islet selectivity, subsequent studies in animal models of autoimmune diabetes yielded further evidence that the lymphocytic infiltration of the islet triggers this nerve loss. For example, in NOD mice, there is a highly significant correlation between the percentage of islet area infiltrated by lymphocytes and the degree of islet sympathetic nerve loss [20] (Fig. 2). Even before diabetes onset, the minority of NOD islets that are heavily infiltrated have fewer sympathetic nerves than the majority of islets which are only sparsely infiltrated [20]. Similarly, in the RIP-GP mouse, there is no loss of islet sympathetic nerves before the islet is infiltrated, yet there is a major loss as soon as the islet becomes heavily infiltrated [22]. The implication of these correlational studies was confirmed by an interventional study: blocking the lymphocytic infiltration of the islet by the administration of complete Freund's adjuvant to NOD mice prevented the loss of islet sympathetic nerves as well as the development of diabetes [20]. Together these findings suggest that the nerve loss in animal models of autoimmune diabetes is linked specifically to the infiltration of the islet by immune cells rather than to the diabetes resulting from this infiltration.

In contrast, a role for lymphocytic infiltration in the loss of islet sympathetic nerves has yet to be demonstrated in humans with type 1 diabetes. A major problem in doing so is the paucity of lymphocytes found in the islets of individuals with type 1 diabetes $[47,48]$. By the time a person presents with

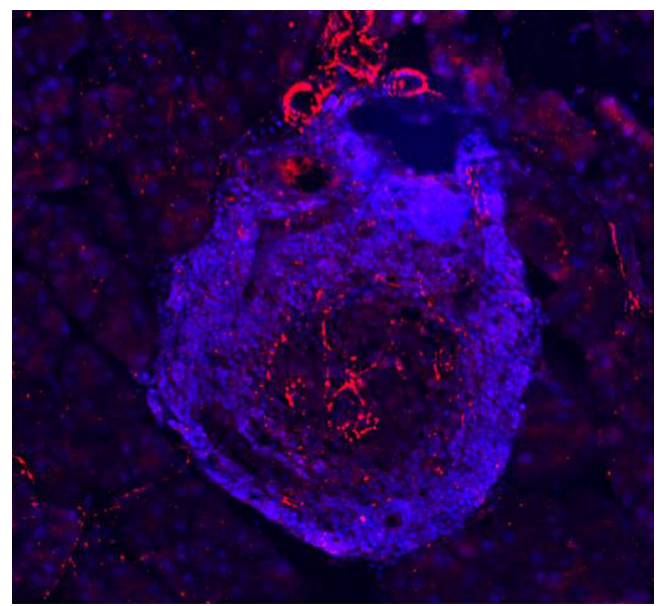

Fig. 2 Invasive insulitis is associated with a loss of islet sympathetic nerves. A single pancreatic islet from a diabetic NOD mouse showing invasive insulitis (small blue cells) and sympathetic axons with varicosities (red lines and dots). Sympathetic neural density is decreased only in the infiltrated part of the islet. Image captured at magnification $\times 20$. (Reproduced from Taborsky et al [85] with permission from John Wiley $\&$ Sons Ltd) type 1 diabetes, the vast majority of lymphocytes that caused the destruction of their beta cells have apparently left the islet [49]. Indeed, immune cells in the islet are usually found only in individuals with very short diabetes duration [50] and then only in very small amounts [48]. Together these findings suggest that in humans with type 1 diabetes insulitis is transient, consistent with the view that it is a relapsing-remitting disease $[51,52]$. Thus, to relate previous episodes of insulitis to the loss of islet sympathetic nerves in human type 1 diabetes, one needs an index of cumulative insulitis. Because the loss of islet beta cells is thought to be due to insulitis, the degree of an islet's beta cell loss is likely an index, albeit an indirect one, of that islet's history of insulitis [53]. Thus, it may be possible to use the degree of beta cell loss to relate 'cumulative insulitis' to the loss of islet sympathetic nerves in human type 1 diabetes. Despite the fact that a relation between insulitis and loss of islet sympathetic nerves has yet to be demonstrated in human type 1 diabetes, there is an autoimmune requirement for the loss of islet sympathetic nerves because there is no loss of islet sympathetic nerves in individuals with type 2 diabetes [23], which is traditionally viewed as a non-autoimmune disease.

\section{Early onset of nerve loss}

While infiltration of the islet is required for the loss of its sympathetic nerves in animal models of autoimmune diabetes, it was not initially clear if the nerve loss was rapid, like that mediated by active pruning [54], or slow, like that due to the chronic neural degeneration seen in classical diabetic autonomic neuropathy (DAN) $[55,56]$. Fortunately, the differing time courses and magnitudes of infiltration found in the various animal models of autoimmune diabetes have answered this question. In the BB rat [19], NOD mouse [20] and RIP-GP mouse [22] islet nerve loss is observed within 1-2 weeks of diabetes onset, suggesting an active and rapid pruning of islet sympathetic nerves. Importantly, in human type 1 diabetes, loss of islet sympathetic nerves has also been demonstrated 1-2 weeks after diabetes onset [23]. Thus, in rats, mice and humans, the islet nerve loss occurs very early in the course of autoimmune diabetes.

The slow and progressive infiltration that precedes diabetic hyperglycaemia in the NOD mouse presents an opportunity to better define the onset of nerve loss. Before diabetes onset, a minority of islets already have evidence of heavy lymphocytic infiltration and those islets also display a marked loss of islet sympathetic nerves [20]. Subsequently, the predictable timing of islet infiltration offered by the inducible diabetes of the RIP-GP mouse has proved to be instrumental in identifying exactly when islet sympathetic nerves are lost. Four days after LCMV injection neither infiltration nor nerve loss is observed in the islets of these mice [22]. However, 7 days after LCMV injection there is a marked infiltration of the islet accompanied 
by marked loss of islet sympathetic nerves [22] despite the fact that diabetic hyperglycaemia does not appear until 2 days later. Thus, we conclude from these studies that islet sympathetic nerves are destroyed coincident with islet infiltration and that by the time enough beta cells are destroyed to produce hyperglycaemia a majority of islet sympathetic nerves have already been lost.

\section{Mechanism of nerve loss}

\section{The role of the $\mathrm{p} 75$ neurotrophin receptor}

Several mechanisms with the potential to cause eSIN have been ruled out. For example, the slow deterioration of nerve function that characterises DAN and somatosensory neuropathy (SSN) differs in two ways from that causing the rapid onset of eSIN. First, DAN and SSN occur in both type 1 and type 2 diabetes, but eSIN occurs only in type 1 diabetes [23]. Second, the development of both DAN and SSN is linked to chronic hyperglycaemia, yet eSIN occurs even before diabetic hyperglycaemia develops [20,22]. Also, in eSIN the loss of islet sympathetic nerves is not caused by the loss of islet beta cells because eSIN does not occur in either ALX-diabetic mice [20] or STZ-diabetic rats [19] who have lost enough beta cells to require insulin treatment. Finally, although the lymphocytic infiltration of the islet somehow triggers eSIN, it is unlikely that invading $\mathrm{T}$ lymphocytes directly attack sympathetic nerves because the parent axons of these islet nerves, which reside in the adjacent exocrine pancreas, remain intact $[19,20,23]$.

The discussion above suggests that the destructive effect of invading lymphocytes on islet sympathetic nerves is indirect, perhaps by activation of pruning receptors on sympathetic axons. Activation of one such receptor, the p75 neurotrophin receptor $\left(\mathrm{p} 75^{\mathrm{NTR}}\right)$, results in the rapid pruning of sympathetic axons in various tissues during late development [54]. To determine whether the $\mathrm{p} 75^{\mathrm{NTR}}$ plays a similar role in the rapid loss of islet sympathetic nerves seen early in autoimmune diabetes, we knocked out p75ntr (also known as $N g f r$ ) in RIP-GP mice [22]. These mice become diabetic after LCMV injection, as do p75ntr wild-type mice, but unlike wild-type mice, $p 75 \mathrm{ntr}$-knockout mice retain their islet sympathetic nerves both immediately before diabetes onset and 3 weeks thereafter [22]. Thus, the lymphocytic attack of the islet causes the loss of both islet sympathetic nerves and islet beta cells, but by different mechanisms. Although these studies established that the $\mathrm{p} 75^{\mathrm{NTR}}$ is required for the loss of islet sympathetic nerves, they did not determine the mechanism by which this receptor is activated in autoimmune diabetes.

\section{Activation of the $p 75^{\mathrm{NTR}}$}

Both ligand-dependent and ligand-independent mechanisms for the activation of the $\mathrm{p} 75^{\mathrm{NTR}}$ have been described in nonislet tissue. With regard to ligand-dependent activation, sympathetic axonal degeneration is seen following activation of the $\mathrm{p} 75^{\mathrm{NTR}}$ by brain-derived neurotrophic factor (BDNF). For example, the cyclic sympathetic denervation of the uterus that occurs during oestrus in rodents is due to cyclic, local expression of BDNF acting on the $\mathrm{p} 75^{\mathrm{NTR}}$ [57]. To determine whether an analogous increase in islet BDNF activates the $\mathrm{p} 75^{\mathrm{NTR}}$, resulting in eSIN, we sought to induce islet infiltration while blocking the hypothesised increase in islet BDNF. We did so by deleting one $B d n f$ allele in RIP-GP mice, which was effective in reducing the basal expression of islet BDNF (Fig. 3). In support of the BDNF hypothesis (Fig. 4), LCMV administration to these mice leads to a retention of islet sympathetic nerves immediately preceding diabetes onset (Fig. 5). However, after 3 weeks of diabetes the loss of islet sympathetic nerves in these $B d n f$ heterozygous RIP-GP mice is equivalent to that of control mice (Fig. 6). Thus, the sparing of islet sympathetic nerves in mice with reduced (but not absent) islet BDNF expression is transient.

It is known from in vitro studies that low levels of NGF are permissive for BDNF to prune sympathetic axons [58] (Fig. 4). Thus, this transient protection could be caused by an increase in NGF production and its subsequent stimulation of the axonal maintenance receptor tropomyosin receptor kinase $\mathrm{A}$, which also resides on sympathetic axons (Fig. 4). We therefore looked for, and found, increased basal NGF expression in $B d n f$ heterozygous islets (Fig. 3). This finding strengthens the possibility that increased NGF helps to protect islet sympathetic nerves from early destruction. Because

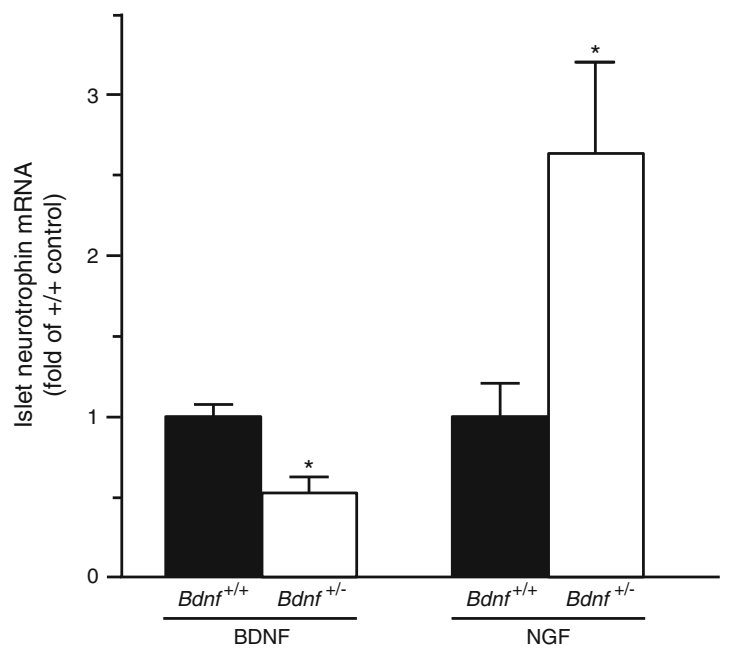

Fig. 3 Basal islet expression of two neurotrophins and the effect of deleting one allele of $B d n f$ thereon. As expected, BDNF expression is reduced by $50 \%$ in $B d n f$ heterozygous $\left(B d n f^{+-}\right.$) mice. Unexpectedly, NGF expression is increased by $150 \%$ in $B d n f^{+/-}$mice. ${ }^{*} p<0.05$ vs wild-type, homozygous $\left(B d n f^{+/+}\right)$control 


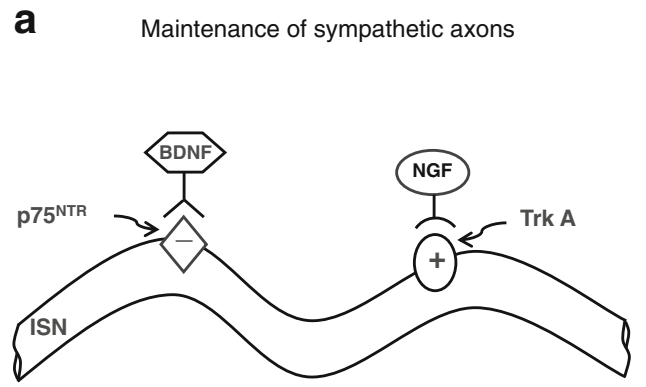

Fig. 4 The role of neurotrophin receptors and their activators in either maintaining (a) or pruning (b) islet sympathetic nerves (ISNs). In the nondiabetic state (a), normal sympathetic innervation of the islet is maintained by a balance between an axonal maintenance signal $(+)$, provided by NGF stimulation of tropomyosin receptor kinase A (Trk A) receptors, and an axonal pruning signal $(-)$, provided by BDNF stimulation of the

several lines of evidence suggest that beta cells are the major [44-46, 59], but not the only [60], source of islet NGF, near complete destruction of these cells by 3 weeks of diabetes may also explain why this early protection of islet sympathetic nerves is not maintained over time. However, studies are needed to quantify the decrease in islet NGF protein that actually results from the autoimmune destruction of islet beta cells and to determine whether the increase in islet NGF seen in Bdnf heterozygotes (Fig. 3) is actually sufficient to protect islet sympathetic nerves. There is also a need for measurements of BDNF in islets before, during and after the onset of autoimmune diabetes to define the respective roles of NGF and BDNF in both the healthy retention and the pathological loss of islet sympathetic nerves. The recent development of a non-viral method to induce autoimmune diabetes in RIP-GP mice [21], which we show here is also

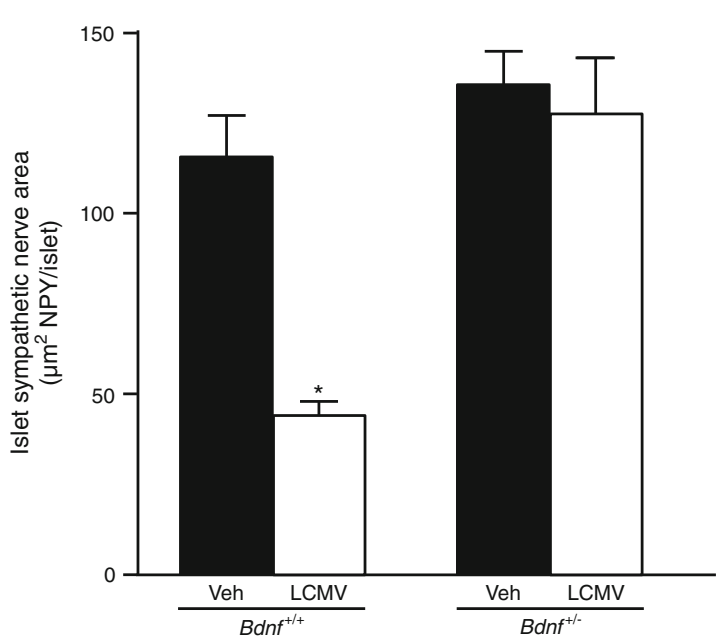

Fig. 5 Deleting one $B d n f$ allele prevents the early loss of islet sympathetic nerves induced by viral injection in RIP-GP mice. In $B d n f$ wild-type mice $\left(B d n f^{+/}\right)$there is a marked loss of islet sympathetic nerves 7 days after LCMV injection that does not occur in $B d n f^{+/-}$mice. NPY, neuropeptide tyrosine. ${ }^{*} p<0.05$ vs vehicle (Veh)-treated control b

b Pruning of sympathetic axons

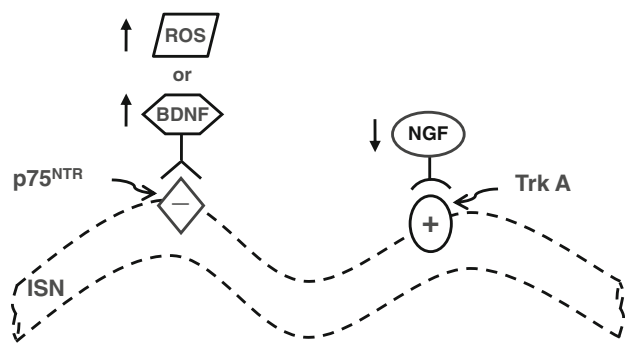

$\mathrm{p} 75^{\mathrm{NTR}}$. During an immune attack on the islet (b), an increase in either islet BDNF or islet ROS increases activation of the $\mathrm{p} 75^{\mathrm{NTR}}$. Simultaneously, a decrease in beta cell-derived NGF reduces the stimulation of Trk A receptors. Together, there is a dramatic shift of the balance toward axonal pruning (dashed lines)

characterised by eSIN (Fig. 1), now increases the feasibility of making such measurements.

With regard to a ligand-independent factor that might activate the $\mathrm{p} 75^{\mathrm{NTR}}$, we searched for one that would be increased during the autoimmune attack on the islet. In vitro studies have shown that reactive oxygen species (ROS) activate $\gamma$-secretase within the cell membrane, which in turn frees the intracellular domain of the $\mathrm{p} 75^{\mathrm{NTR}}$ for downstream signalling [61]. More recent studies demonstrate that this ligand-independent activation of $\mathrm{p} 75^{\mathrm{NTR}}$ also results in axonal degeneration, at least in vitro [62]. Such a mechanism of $\mathrm{p} 75^{\mathrm{NTR}}$ activation is plausible in autoimmune diabetes because ROS is known to be generated in islets under autoimmune attack [63] (see also Fig. 4). Further, the reagents needed to test this proposed mechanism are available since inhibitors of $\gamma$-secretase have been developed as a potential treatment for Alzheimer's disease [64]. However, more selective Notch-sparing $\gamma$-secretase inhibitors

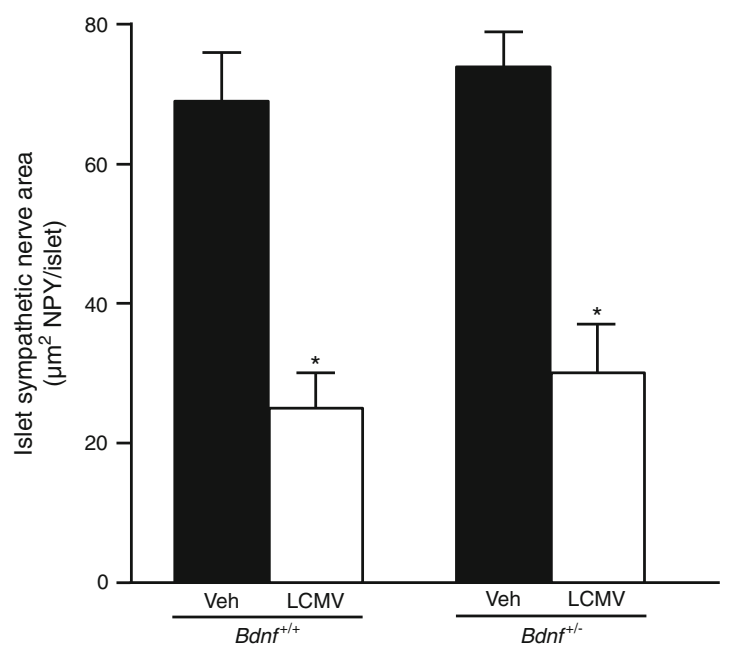

Fig. 6 Deleting one $B d n f$ allele does not prevent the later loss of islet sympathetic nerves induced by viral injection in RIP-GP mice. In $B d n f^{+/}$ mice there is a marked loss of islet sympathetic nerves after 3 weeks of LCMV-induced diabetes that is identical to that seen in Bdnf wild-type mice $\left(B d n f^{+/+}\right)$. NPY, neuropeptide tyrosine. ${ }^{*} p<0.05$ vs vehicle (Veh)treated control 
[65] are required for use in animal models of autoimmune diabetes: Notch, another substrate for $\gamma$-secretase, is involved in the development and maturation of the lymphocytes [66] that cause autoimmune diabetes [67]. If islet ROS activates the p $75^{\text {NTR }}$ by this ligand-independent mechanism, then Notchsparing inhibition of $\gamma$-secretase should prevent the loss of islet sympathetic nerves during the immune attack on the islet.

In summary, although $\mathrm{p} 75^{\mathrm{NTR}}$ is required for the loss of islet sympathetic nerves during the immune attack on the islet, the molecules and pathways responsible for activating this receptor in autoimmune diabetes have yet to be convincingly demonstrated. However, it is worth noting that the link between immune cell infiltration and loss of sympathetic nerves is not restricted to autoimmune diabetes. For example, there is a loss of sympathetic nerves in the inflamed intestine of patients with Crohn's disease [68] and in the inflamed joints of patients with rheumatoid arthritis [69]. The common factor in the loss of sympathetic nerves among these three diseases is the infiltrate, not the tissues infiltrated. Thus, to activate the $\mathrm{p} 75^{\mathrm{NTR}}$, the invading lymphocytes either secrete BDNF or induce the production of BDNF or ROS in a tissue-independent fashion.

\section{Functional consequences of nerve loss}

\section{Impaired glucagon response to sympathetic activation}

In both diabetic $\mathrm{BB}$ rats and diabetic NOD mice, the major loss of islet sympathetic nerves results in a marked impairment of the glucagon response to either electrical [70] or chemical [20] activation of postganglionic sympathetic nerves. The findings in these models directly demonstrate the functional consequence of this nerve loss. However, because the islet nerve loss in human type 1 diabetes has only recently been demonstrated [23], the effect of this nerve loss on sympathetically mediated glucagon secretion in humans has yet to be determined.

The impaired glucagon response to sympathetic neural activation is not due to dysfunctional alpha cells because adrenaline elicits a normal glucagon response in BB diabetic rats [70] and an exaggerated glucagon response in humans with type 1 diabetes [71]. The hyper-response in humans may be due to an upregulation of adrenergic receptors on the alpha cell, secondary to loss of islet sympathetic nerves, but experiments specifically designed to directly test this hypothesis are needed. This glucagon impairment is due neither to loss of beta cells nor to diabetic hyperglycaemia because when both are induced by non-immune, chemical destruction of islet beta cells, which does not cause loss of islet sympathetic nerves, the glucagon response to activation of postganglionic sympathetic axons and terminals is not impaired [20,30]. In contrast, the glucagon impairment seen in autoimmune diabetes, which does cause the loss of islet sympathetic nerves, is likely due to decreased neurotransmitter release. In support of this interpretation, pre-treating non-diabetic rodents with 6-hydroxydopamine, which reproduces the degree of islet sympathetic nerve loss seen in diabetic BB rats, NOD mice and RIP-GP mice, markedly decreases the release of the sympathetic neurotransmitter noradrenaline (norepinephrine) and reproduces the impairment of the glucagon response to postganglionic sympathetic neural activation seen in these models of autoimmune diabetes $[20,22,70]$.

\section{Impaired glucagon response to insulin-induced hypoglycaemia}

Individuals with type 1 diabetes have an impaired glucagon response to IIH within the first year after diagnosis [7]. Pancreatic sympathetic nerves in non-diabetic animals are activated during marked and severe hypoglycaemia (glucose $\approx 1.9 \mathrm{mmol} / 1$ and $\approx 0.8 \mathrm{mmol} / 1$, respectively) $[72,73]$. Hence, the loss of islet sympathetic nerves in humans with type 1 diabetes is a potential contributor to the impaired glucagon responses seen at these levels of hypoglycaemia. Consistent with this interpretation, individuals with type 2 diabetes, who do not lose islet sympathetic nerves [23], have a normal glucagon response to IIH, at least for the first decade after diabetes diagnosis [74].

In contrast, because the pancreatic sympathetic nerves of non-diabetic animals are not activated by mild hypoglycaemia (glucose $\approx 3.9 \mathrm{mmol} / \mathrm{l}$ ), eSIN cannot account for the impairment of the glucagon response seen in diabetic animals at this level of hypoglycaemia [75]. However, factors intrinsic to the alpha cell have been shown to stimulate glucagon secretion when glucose levels fall, and these factors may be impaired in diabetes [76]. Similarly, diabetes-induced changes in islet paracrine factors, such as somatostatin and insulin, may also account for the alpha cell's impaired response to mild hypoglycaemia. For example, blocking the action of somatostatin from neighbouring islet delta cells improves the glucagon response to hypoglycaemia in diabetic animals [77]. Also, insulin or other beta cell secretory products (68-70) are thought to tonically restrain glucagon secretion. Because even mild hypoglycaemia is sufficient to totally inhibit insulin secretion in non-diabetic individuals [78], mild hypoglycaemia may eliminate the tonic inhibitory effects of the beta cell on adjacent alpha cells [79]. Loss of this beta cell switch-off in diabetic animals could therefore impair the glucagon response to mild hypoglycaemia $[75,80]$. However, it is unlikely to account for the major impairment of the larger glucagon responses seen at marked or severe hypoglycaemia for the following reasons. In non-diabetic humans and animals there is no further decrease of insulin at these levels of hypoglycaemia, implying that the larger glucagon responses seen are due to recruitment of other stimulatory factors as hypoglycaemia deepens [15]. Therefore, diabetesinduced defects in these other factors, including islet 
sympathetic nerves, are likely responsible for the glucagon impairment at these levels of hypoglycaemia.

Relative contribution of eSIN While the data above would suggest that the relative contributions made by eSIN and intrinsic and paracrine factors to the impaired glucagon response to IIH depend on the severity of hypoglycaemia, a definitive study of their relative contribution has yet to be performed. Currently, there are barriers to correctly performing and correctly interpreting such studies In particular, the inhibitory effect of short-term diabetic hyperglycaemia on sympathetic ganglia and the inhibitory effect of exogenous insulin on alpha cell responsiveness must be accounted for. A recent study has shown that even 1 week of severe hyperglycaemia can impair neurotransmission across coeliac ganglia [30]. Since coeliac ganglia project sympathetic nerves to the pancreas [81], such impaired ganglionic neurotransmission results in the impairment of sympathetically mediated glucagon responses when preganglionic nerves are activated [30]. This implies that previous conclusions that the impaired glucagon response to $\mathrm{IIH}$ in diabetic animals is due solely to loss of beta cell switch-off may need to be amended to include the contribution of a previously unrecognised impairment in the sympathetic islet pathway.

In addition, exogenous insulin is known to decrease the responsiveness of the alpha cell to stimuli [82, 83] and this inhibitory effect of exogenous insulin may be increased in type 1 diabetes [84]. Thus, even when the degree of hypoglycaemia is experimentally matched between nondiabetic individuals and those with type 1 diabetes, one needs to experimentally match the inhibitory effect of exogenous insulin per se on glucagon secretion in the two groups. Therefore, to determine the contribution made by eSIN to the impairment of the glucagon response to IIH, the experimental design must account for the following: (1) the severity of the hypoglycaemia; (2) the inhibitory effect of prior hyperglycaemia on sympathetic ganglionic neurotransmission and (3) the inhibitory effect of exogenous insulin on the responsiveness of the alpha cell.

\section{Summary and future directions}

A comprehensive summary of studies of the characteristics, mechanism and functional consequences of eSIN is provided in Table 1. In brief, there is an early, marked and islet-selective loss of sympathetic nerves both in animal models of autoimmune diabetes and in humans with type 1 diabetes. This nerve loss is sufficient to impair sympathetically mediated glucagon secretion in animals and may contribute to the impaired glucagon response to IIH seen in humans with type 1 diabetes. Lymphocytic infiltration of the islet and subsequent activation of the $\mathrm{p} 75^{\mathrm{NTR}}$ are required for the nerve loss, at least in animal models of autoimmune diabetes.

Future studies to define the agonist or activator of the $\mathrm{p} 75^{\mathrm{NTR}}$ are needed to complete our understanding of the mechanism by which eSIN occurs. Further studies are also needed to determine the contribution of eSIN to the impaired glucagon response to $\mathrm{IIH}$, in both human type 1 diabetes and in animal models thereof. Such studies would solidify the clinical relevance of eSIN. However, such experiments must be carefully designed to account for ganglionic impairment, a second dysfunction within the islet sympathetic pathway. Finally, since eSIN occurs before the onset of overt diabetes, future studies should focus on reversing, rather than preventing, this unique neuropathy.

Acknowledgements We thank M. Bothwell, University of Washington, for helpful discussions regarding ROS and $\mathrm{p} 75^{\mathrm{NTR}}$ activation, and our colleagues at the VA Puget Sound Health Care System and the University of Washington for providing helpful advice on this manuscript. We thank P. Banik, University of Washington, for performing the RT-PCR analysis of islet extracts. In addition, we thank D. Hackney, VA Puget Sound Health Care System, for performing the complex, non-viral induction of diabetes in RIP-GP mice and Q. Mei, University of Washington, for immunohistochemical determination of islet nerve area in these mice. Finally, we kindly thank P. Henderson, VA Puget Sound Health Care System, for administrative assistance.

Funding The studies to determine basal islet expression of BDNF and NGF were performed in part at the Cell Function Analysis Core of the University of Washington's Diabetes Research Center, which is supported by NIH grant no. P30-DK-017047. This work was supported by a Merit Review from the Biomedical Laboratory R\&D Service of the US Department of Veterans Affairs and by US National Institute of Health grant no. R01-DK-050154.

Contribution statement Both authors contributed significantly to the intellectual content of this article, wrote the manuscript and approved this version for publication.

Duality of interest The authors declare that there is no duality of interest associated with this manuscript.

\section{References}

1. Bliss M (2007) The discovery of insulin. University of Chicago Press, Chicago

2. Kimball CP, Murlin JR (1923) Aqueous extracts of pancreas III. Some precipitation reactions of insulin. J Biol Chem 58:337-348

3. Gerich J, Schneider V, Dippe S et al (1974) Characterization of the glucagon response to hypoglycemia in man. J Clin Endocrinol Metab 38:77-82

4. Gerich J, Davis J, Lorenzi M et al (1979) Hormonal mechanisms of recovery from insulin-induced hypoglycemia in man. Am J Physiol 236:E380-E385

5. Cryer PE, Gerich J (1983) Relevance of glucose counterregulatory systems to patients with diabetes: critical roles of glucagon and epinephrine. Diabetes Care 6:95-99 
6. Gerich J, Langlois M, Noacco C, Karam J, Forsham P (1973) Lack of glucagon response to hypoglycemia in diabetes: evidence for an intrinsic pancreatic alpha cell defect. Science 182:171-173

7. Arbelaez AM, Xing D, Cryer PE et al (2014) Blunted glucagon but not epinephrine responses to hypoglycemia occurs in youth with less than 1 yr duration of type 1 diabetes mellitus. Pediatr Diabetes 15:127-134

8. Bohme P, Bertin E, Cosson E, Chevalier N, group G (2013) Fear of hypoglycaemia in patients with type 1 diabetes: do patients and diabetologists feel the same way? Diabetes Metab 39:63-70

9. McCrimmon RJ, Sherwin RS (2010) Hypoglycemia in type 1 diabetes. Diabetes 59:2333-2339

10. Frier BM (2008) How hypoglycaemia can affect the life of a person with diabetes. Diabetes Metab Res Rev 24:87-92

11. DCCT (1993) The effect of intensive treatment of diabetes on the development and progression of long-term complications in insulin-dependent diabetes mellitus. The Diabetes Control and Complications Trial Research Group. N Engl J Med 329:977-986

12. Aiello LP, Sun W, Das A et al (2015) Intensive diabetes therapy and ocular surgery in type 1 diabetes. N Engl J Med 372:1722-1733

13. de Boer IH, Sun W, Cleary PA et al (2011) Intensive diabetes therapy and glomerular filtration rate in type 1 diabetes. N Engl J Med 365:2366-2376

14. Nathan DM, Cleary PA, Backlund JY et al (2005) Intensive diabetes treatment and cardiovascular disease in patients with type 1 diabetes. N Engl J Med 353:2643-2653

15. Taborsky GJ Jr, Mundinger TO (2012) The role of the autonomic nervous system in mediating the glucagon response to hypoglycemia. Endocrinology 153:1055-1062

16. Havel PJ, Ahren B (1997) Activation of autonomic nerves and the adrenal medulla contributes to increased glucagon secretion during moderate insulin-induced hypoglycemia in women. Diabetes 46: 801-807

17. Hoffman RP, Singer-Granick C, Drash AL, Becker DJ (1994) Abnormal alpha cell hypoglycemic recognition in children with insulin dependent diabetes mellitus (IDDM). J Pediatr Endocrinol 7:225-234

18. Bolli G, De Feo P, Compagnucci P et al (1983) Abnormal glucose counterregulation in insulin-dependent diabetes mellitus: interaction of anti-insulin antibodies and impaired glucagon and epinephrine secretion. Diabetes 32:134-141

19. Mei Q, Mundinger TO, Lernmark A, Taborsky GJ Jr (2002) Early, selective, and marked loss of sympathetic nerves from the islets of BioBreeder diabetic rats. Diabetes 51:2997-3002

20. Taborsky GJ Jr, Mei Q, Hackney DJ, Figlewicz DP, LeBoeuf R, Mundinger TO (2009) Loss of islet sympathetic nerves and impairment of glucagon secretion in the NOD mouse: relationship to invasive insulitis. Diabetologia 52:2602-2611

21. Martinic MM, von Herrath MG (2008) Real-time imaging of the pancreas during development of diabetes. Immunol Rev 221:200 213

22. Taborsky GJ Jr, Mei Q, Bornfeldt KE, Hackney DJ, Mundinger TO (2014) The p75 neurotrophin receptor is required for the major loss of sympathetic nerves from islets under autoimmune attack. Diabetes 63:2369-2379

23. Mundinger TO, Mei Q, Foulis AK, Fligner CL, Hull RL, Taborsky GJ Jr (2016) Human type 1 diabetes is characterized by an early, marked, sustained and islet-selective loss of sympathetic nerves. Diabetes. doi:10.2337/db16-0284

24. Erickson JD, Schafer MH, Bonner TI, Eiden LE, Weihe E (1996) Distinct pharmacological properties and distribution in neurons and endocrine cells of two isoforms of the human vesicular monoamine transporter. Proc Natl Acad Sci 93:5166-5171

25. Allen R, Boublik J, Hauger RL, Scott N, Rivier J, Brown MR (1991) Neuropeptide Y radio-immunoassay: characterization and application. Clin Exp Pharmacol Physiol 18:825-833
26. De Potter WP, Dillen L, Annaert W, Tombeur R, Berghmans R, Coen EP (1988) Evidence for the co-storage and co-release of neuropeptide $\mathrm{Y}$ and noradrenaline from large dense core vesicles in sympathetic nerves of the bovine vas deferens. Synapse 2:157-162

27. Anlauf M, Eissele R, Schafer MK et al (2003) Expression of the two isoforms of the vesicular monoamine transporter (VMAT1 and VMAT2) in the endocrine pancreas and pancreatic endocrine tumors. J Histochem Cytochem 51:1027-1040

28. Upchurch BH, Aponte GW, Leiter AB (1994) Expression of peptide $\mathrm{YY}$ in all four islet cell types in the developing mouse pancreas suggests a common peptide YY-producing progenitor. Development 120:245-252

29. Korsgren O, Andersson A, Jansson L, Sundler F (1992) Reinnervation of syngeneic mouse pancreatic islets transplanted into renal subcapsular space. Diabetes 41:130-135

30. Mundinger TO, Cooper E, Coleman MP, Taborsky GJ Jr (2015) Short-term diabetic hyperglycemia suppresses celiac ganglia neurotransmission, thereby impairing sympathetically mediated glucagon responses. Am J Physiol Endocrinol Metab 309:E246-E255

31. Scheib J, Hoke A (2013) Advances in peripheral nerve regeneration. Nat Rev Neurol 9:668-676

32. Kennedy JM, Zochodne DW (2005) Impaired peripheral nerve regeneration in diabetes mellitus. J Peripher Nerv Syst 10:144-157

33. Saleh A, Chowdhury SK, Smith DR et al (2013) Diabetes impairs an interleukin-1 $\beta$-dependent pathway that enhances neurite outgrowth through JAK/STAT3 modulation of mitochondrial bioenergetics in adult sensory neurons. Mol Brain 6:45

34. Saleh A, Roy Chowdhury SK, Smith DR et al (2013) Ciliary neurotrophic factor activates NF-kB to enhance mitochondrial bioenergetics and prevent neuropathy in sensory neurons of streptozotocin-induced diabetic rodents. Neuropharmacology 65: 65-73

35. Fernyhough P, Jonathan M (2014) Mechanisms of disease: mitochondrial dysfunction in sensory neuropathy and other complications in diabetes. Handb Clin Neurol 126:353-377

36. Chowdhury SK, Smith DR, Fernyhough P (2013) The role of aberrant mitochondrial bioenergetics in diabetic neuropathy. Neurobiol Dis 51:56-65

37. Ali S, Driscoll HE, Newton VL, Gardiner NJ (2014) Matrix metalloproteinase-2 is downregulated in sciatic nerve by streptozotocin induced diabetes and/or treatment with minocycline: implications for nerve regeneration. Exp Neurol 261:654-665

38. Dey I, Midha N, Singh G et al (2013) Diabetic Schwann cells suffer from nerve growth factor and neurotrophin-3 underproduction and poor associability with axons. Glia 61:1990-1999

39. Gumy LF, Bampton ET, Tolkovsky AM (2008) Hyperglycaemia inhibits Schwann cell proliferation and migration and restricts regeneration of axons and Schwann cells from adult murine DRG. Mol Cell Neurosci 37:298-311

40. Eckersley L (2002) Role of the Schwann cell in diabetic neuropathy. Int Rev Neurobiol 50:293-321

41. Stenberg L, Dahlin LB (2014) Gender differences in nerve regeneration after sciatic nerve injury and repair in healthy and in type 2 diabetic Goto-Kakizaki rats. BMC Neurosci 15:107

42. Singh B, Singh V, Krishnan A et al (2014) Regeneration of diabetic axons is enhanced by selective knockdown of the PTEN gene. Brain 137:1051-1067

43. Edwards RH, Rutter WJ, Hanahan D (1989) Directed expression of NGF to pancreatic B cells in transgenic mice leads to selective hyperinnervation of the islets. Cell 58:161-170

44. Rosenbaum T, Vidaltamayo R, Sanchez-Soto MC, Zentella A, Hiriart M (1998) Pancreatic B cells synthesize and secrete nerve growth factor. Proc Natl Acad Sci U S A 95:7784-7788

45. Navarro-Tableros V, Sanchez-Soto MC, Garcia S, Hiriart M (2004) Autocrine regulation of single pancreatic $\beta$-cell survival. Diabetes 53:2018-2023 
46. Myersen U, Keymeulen B, Pipeleers DG, Sundler F (1996) Beta cells are important for islet innervation: evidence from purified rat islet-cells grafts. Diabetologia 39:54-59

47. In't Veld P (2011) Insulitis in human type 1 diabetes: the quest for an elusive lesion. Islets 3:131-138

48. Campbell-Thompson ML, Atkinson MA, Butler AE et al (2013) The diagnosis of insulitis in human type 1 diabetes. Diabetologia 56:2541-2543

49. Campbell-Thompson M, Fu A, Kaddis JS et al (2016) Insulitis and $\beta$-cell mass in the natural history of type 1 diabetes. Diabetes 65 : 719-731

50. Foulis AK, Stewart JA (1984) The pancreas in recent-onset type 1 (insulin-dependent) diabetes mellitus: insulin content of islets, insulitis and associated changes in the exocrine acinar tissue. Diabetologia 26:456-461

51. von Herrath M, Sanda S, Herold K (2007) Type 1 diabetes as a relapsing-remitting disease? Nat Rev Immunol 7:988-994

52. Eisenbarth GS, Connelly J, Soeldner JS (1987) The natural history of type I diabetes. Diabetes Metab Rev 3:873-891

53. Willcox A, Richardson SJ, Bone AJ, Foulis AK, Morgan NG (2009) Analysis of islet inflammation in human type 1 diabetes. Clin Exp Immunol 155:173-181

54. Singh KK, Park KJ, Hong EJ et al (2008) Developmental axon pruning mediated by BDNF-p75NTR-dependent axon degeneration. Nat Neurosci 11:649-658

55. Schmidt RE, Plurad SB, Modert CW (1983) Experimental diabetic autonomic neuropathy: characterization in STZ-diabetic SpragueDawley rats. Lab Invest 49:538-552

56. Yagihashi S, Sima AA (1985) Diabetic autonomic neuropathy. The distribution of structural changes in sympathetic nerves of the BB rat. Am J Pathol 121:138-147

57. Krizsan-Agbas D, Pedchenko T, Hasan W, Smith PG (2003) Oestrogen regulates sympathetic neurite outgrowth by modulating brain derived neurotrophic factor synthesis and release by the rodent uterus. Eur J Neurosci 18:2760-2768

58. Kohn J, Aloyz RS, Toma JG, Haak-Frendscho M, Miller FD (1999) Functionally antagonistic interactions between the TrkA and p75 neurotrophin receptors regulate sympathetic neuron growth and target innervation. J Neurosci 19:5393-5408

59. Juang JH, Peng SJ, Kuo CH, Tang SC (2014) Three-dimensional islet graft histology: panoramic imaging of neural plasticity in sympathetic reinnervation of transplanted islets under the kidney capsule. Am J Physiol Endocrinol Metab 306:E559-E570

60. Benner C, van der Meulen T, Caceres E, Tigyi K, Donaldson C, Huising M (2014) The transcriptional landscape of mouse beta cells compared to human beta cells reveals notable species differences in long non-coding RNA and protein-coding gene expression. BMC Genomics 15:620-636

61. Kanning KC, Hudson M, Amieux PS, Wiley JC, Bothwell M, Schecterson LC (2003) Proteolytic processing of the p75 neurotrophin receptor and two homologs generates Cterminal fragments with signaling capability. J Neurosci 23: $5425-5436$

62. Kraemer BR, Snow JP, Vollbrecht P et al (2014) A role for the $\mathrm{p} 75$ neurotrophin receptor in axonal degeneration and apoptosis induced by oxidative stress. J Biol Chem 289:21205-21216

63. Padgett LE, Broniowska KA, Hansen PA, Corbett JA, Tse HM (2013) The role of reactive oxygen species and proinflammatory cytokines in type 1 diabetes pathogenesis. Ann N Y Acad Sci 1281: $16-35$

64. Barten DM, Meredith JE Jr, Zaczek R, Houston JG, Albright CF (2006) Gamma-secretase inhibitors for Alzheimer's disease: balancing efficacy and toxicity. Drugs R D 7:87-97

65. Augelli-Szafran CE, Wei HX, Lu D et al (2010) Discovery of notchsparing gamma-secretase inhibitors. Curr Alzheimer Res 7:207209
66. Radtke F, Fasnacht N, Macdonald HR (2010) Notch signaling in the immune system. Immunity 32:14-27

67. Ma D, Zhu Y, Ji C, Hou M (2010) Targeting the Notch signaling pathway in autoimmune diseases. Expert Opin Ther Targets 14: $553-565$

68. Straub RH, Grum F, Strauch U et al (2008) Anti-inflammatory role of sympathetic nerves in chronic intestinal inflammation. Gut 57: 911-921

69. Miller LE, Justen HP, Scholmerich J, Straub RH (2000) The loss of sympathetic nerve fibers in the synovial tissue of patients with rheumatoid arthritis is accompanied by increased norepinephrine release from synovial macrophages. FASEB J 14:2097-2107

70. Mundinger TO, Mei Q, Figlewicz DP, Lernmark A, Taborsky GJ Jr (2003) Impaired glucagon response to sympathetic nerve stimulation in the BB diabetic rat: effect of early sympathetic islet neuropathy. Am J Physiol Endocrinol Metab 285:E1047-E1054

71. Benson JW Jr, Johnson DG, Palmer JP, Werner PL, Ensinck JW (1977) Glucagon and catecholamine secretion during hypoglycemia in normal and diabetic man. J Clin Endocrinol Metab 44:459464

72. Dunning BE, Scott MF, Neal DW, Cherrington AD (1997) Direct quantification of norepinephrine spillover and hormone output from the pancreas of the conscious dog. Am J Physiol 272:E746-E755

73. Havel PJ, Mundinger TO, Taborsky GJ Jr (1996) Pancreatic sympathetic nerves contribute to increased glucagon secretion during severe hypoglycemia in dogs. Am J Physiol 270:E20-E26

74. Heller SR, Macdonald IA, Tattersall RB (1987) Counterregulation in type 2 (non-insulin-dependent) diabetes mellitus. Normal endocrine and glycaemic responses, up to ten years after diagnosis. Diabetologia 30:924-929

75. Sherck SM, Shiota M, Saccomando J et al (2001) Pancreatic response to mild non-insulin-induced hypoglycemia does not involve extrinsic neural input. Diabetes 50:2487-2496

76. Rorsman P, Salehi SA, Abdulkader F, Braun M, MacDonald PE (2008) $\mathrm{K}_{\mathrm{ATP}}$-channels and glucose-regulated glucagon secretion. Trends Endocrinol Metab 19:277-284

77. Gaisano HY, Macdonald PE, Vranic M (2012) Glucagon secretion and signaling in the development of diabetes. Front Physiol $3: 349$

78. Banarer S, McGregor VP, Cryer PE (2002) Intraislet hyperinsulinemia prevents the glucagon response to hypoglycemia despite an intact autonomic response. Diabetes 51:958-965

79. Zhou H, Tran PO, Yang S et al (2004) Regulation of alpha-cell function by the $\beta$-cell during hypoglycemia in Wistar rats: the switch-off hypothesis. Diabetes 53:1482-1487

80. Raju B, Cryer PE (2005) Loss of the decrement in intraislet insulin plausibly explains loss of the glucagon response to hypoglycemia in insulin-deficient diabetes: documentation of the intraislet insulin hypothesis in humans. Diabetes 54:757-764

81. Quinson N, Robbins HL, Clark MJ, Furness JB (2001) Locations and innervation of cell bodies of sympathetic neurons projecting to the gastrointestinal tract in the rat. Arch Histol Cytol 64:281-294

82. Liu DT, Adamson UC, Lins P-ES, Kollind ME, Moberg EA, Andréasson K (1992) Inhibitory effect of circulating insulin on glucagon secretion during hypoglycemia in type 1 diabetic patients. Diabetes Care 15:59-65

83. Igawa K, Mugavero M, Shiota M, Neal DW, Cherrington AD (2002) Insulin sensitively controls the glucagon response to mild hypoglycemia in the dog. Diabetes 51:3033-3042

84. Asplin CM, Paquette TL, Palmer JP (1981) In vivo inhibition of glucagon secretion by paracrine beta cell activity in man. J Clin Invest 68:314-318

85. Taborsky GJ, Mei Q, Hackney DJ, Mundinger TO (2014) The search for the mechanism of early sympathetic islet neuropathy in autoimmune diabetes. Diabetes Obes Metab 16(Suppl 1): 96-101 